

\title{
The other C Word - Covid - Dealing With the Lack of Closure
}

\author{
Monica Hickson
}

Keywords: Covid - Closure- Pandemic- Crisis- Loss- Love

\section{Abstract}

Dealing with grief is hard no matter the person, length of illness, or the time period. Death during COVID19 is not the same and the impact of the loss is more than just the death of a loved one but the way we mourn moving forward.

\section{The Covid Diaries - The Last Days of My Normal}

In this book Monica Hickson - freelance writer, instructional designer and life-long learner aims to help people understand that which can't be understood.

Monica Website www.monicahickson.com

\section{Dealing with the Lack of Closure}

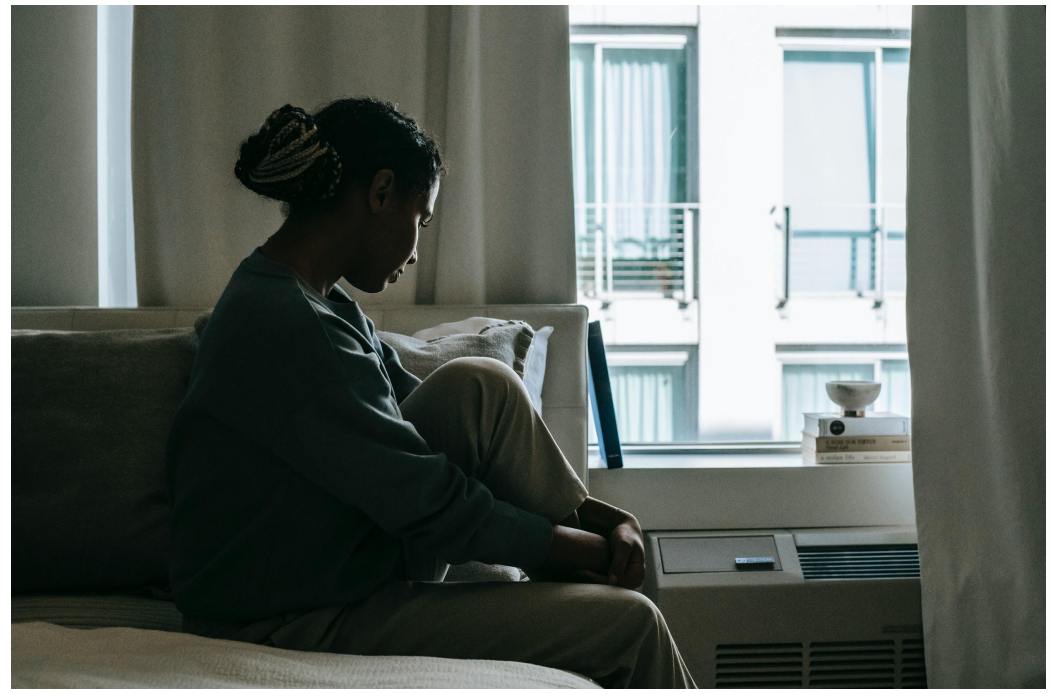


"There is no me without you" - a cliche that is often referred to when speaking about lovers. Looking at his pictures defined a time in my life that was incredible, and for some reason I thought that I had been the source of my own happiness. It was long after he died that I realized that I was not the one that made my life incredible and adventurous but it was him. It was him that built me up and lifted my spirits when I was losing hope. It was him who encouraged me to build a home from the ground up so my son would have a better way of life. It was him that encouraged me to finish writing my book. No one else encouraged me the way that he did.

When my mother died of cancer "the ' $C$ ' word," people surrounded me with warm smiles, pound cake and spaghetti that someone brought over to comfort me during my time of grief. When my fiance died things were different. During a pandemic, and in the age of social distancing the ones that could comfort you could only drive by in a caravan of cars like a parade moving through a rural town. With people holding signs while driving slowly down my block that said, "RIP David we love you", as members of my family slowly traveled down my suburban street to offer condolences to the man I was supposed to spend the rest of my life with.

"It takes time to heal", "I know it is hard", "You will never get over it but it will get better", were all sentiments that were uttered at one point or another as I tried to get over what seemed like a sci-fi horror movie in the making. See this time was unlike any other that I had experienced before, I took my fiance to the hospital where tents were set up outside while nurses came with wheelchairs and disembarked on my car. I remember uttering the words - COVID to the nurses while they just said, "Here is where you say good-bye", as my fiance and I looked at each other we both said, ugh no, "See you later". These were the last words that I would ever speak to him.

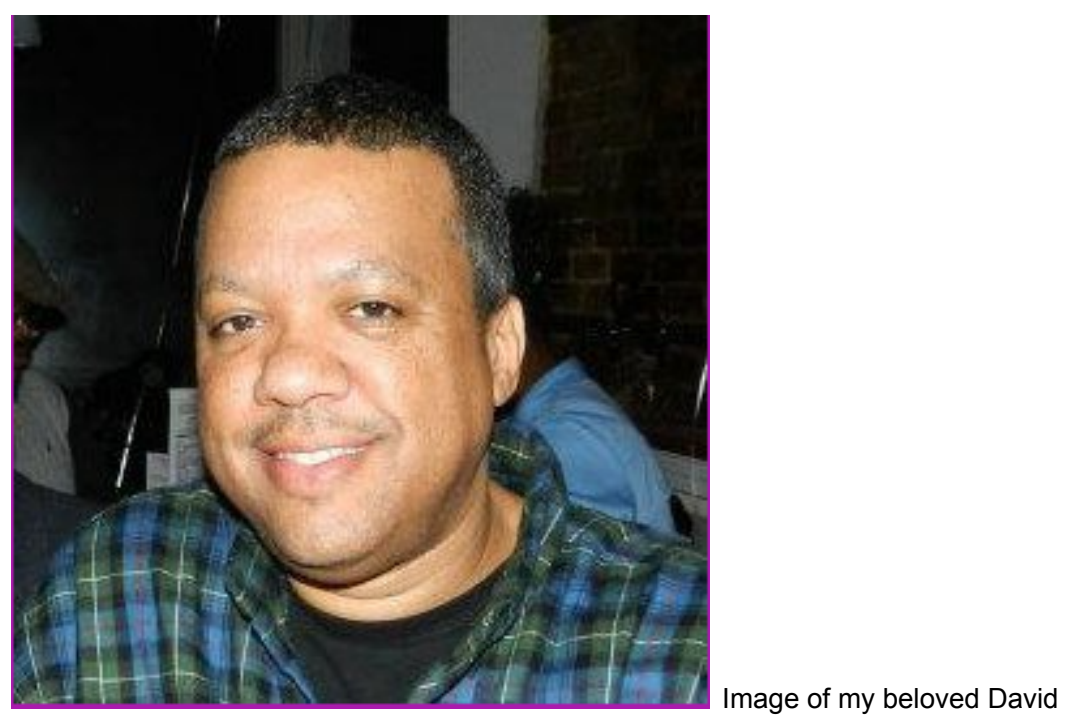

In the next 21 days to follow, I had to wait sometimes 8-12 hours on an update from the doctors to see if he was still breathing with the help of the ventilator. The days became like long nightmares that never ceased to end. At the beginning of the 22nd day, he was gone. That was it. I was not able to go see him because I, myself, was at high risk to 
contract the deadly disease. Just like that in a flash of what appeared to be seconds was the end of his life.

What followed next was even more tragic. I arrived at the funeral home the next day hoping that I would be able to see him once he was brought over from the hospital but the funeral director said due to this highly contagious disease that I still at the end of his life couldn't see him. I was never able to have a funeral for him, after all, no one wanted to be around anyone during the first days of quarantine and nor could they be. So there I was left alone to suffer with my son, no good-bye's, no burial, no memorial, no one throwing themselves on the casket in tears. It was done without any sort of closure or farewell.

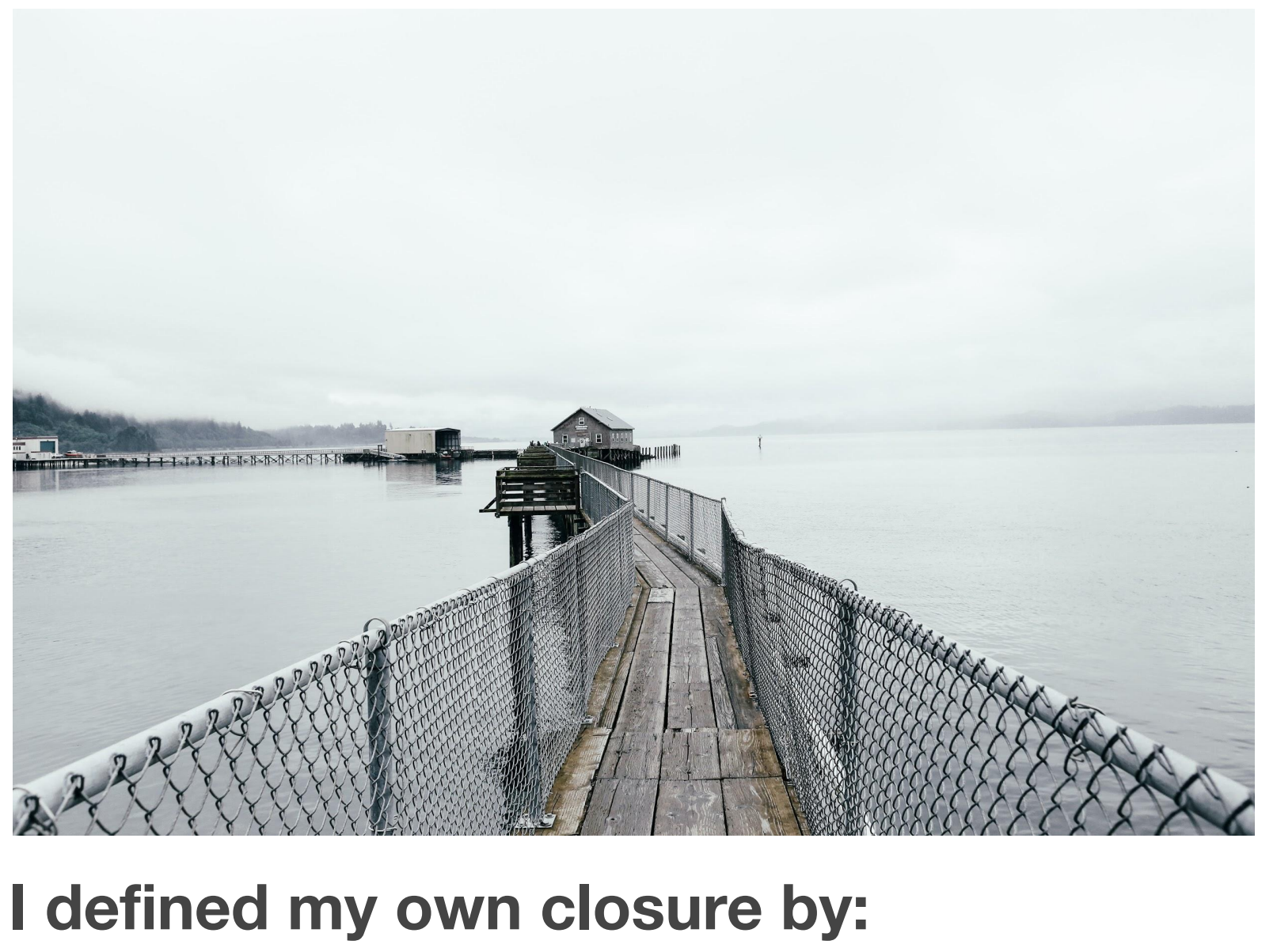

Learning to forgive - Forgive myself and him for any mistakes that might have been real or made up in the mind of a grieving heart. Learning to let small stuff go and understand that nothing can be changed.

Saying goodbye - Understanding that even though it does not seem real that he will never come back. Trying to process the reasons why he left and what happened. Trying not to blame a broken system for the delay in results and try to understand that there is a reason for everything - or so everyone says. 
Learning to love myself - Learning to let go of some of the challenges when you can't say good-bye, can't get closure and never be able to get the answers that you want and desperately seek.

I still cry every single day and pray for answers every single night. I have been told that I might not ever get those answers and that is yet another question of why. Time heals but not all wounds close as easily as the last scars.

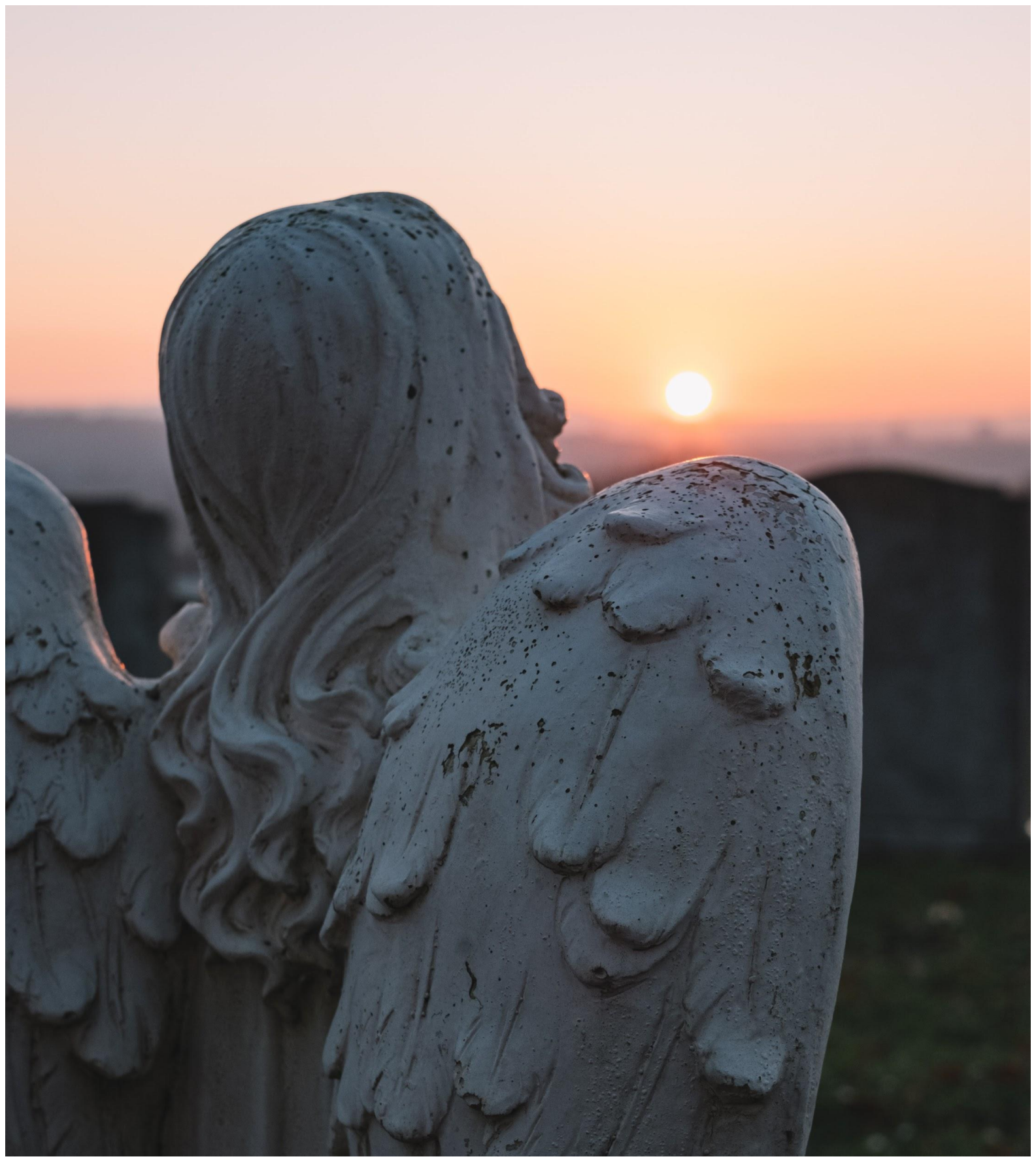




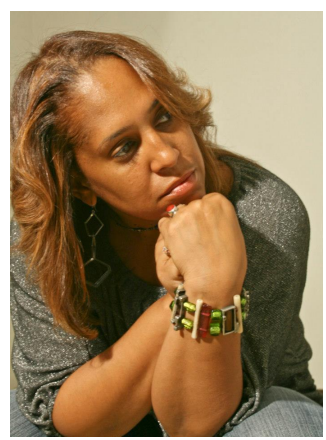

\section{About Monica}

A true multitasker, Monica is a writer, instructional designer, diversity trainer \& facilitator, and educator who likes to stay abreast on a variety of topics. After losing her fiance to COVID-19 she has become an advocate for the people who have suffered during the pandemic and has written several articles and a book highlighting this turbulent time in our history.

You can find her original works and articles on Medium, Zora, The Shadow and several articles in Concentrate. Monica has been featured in several articles about the loss of her

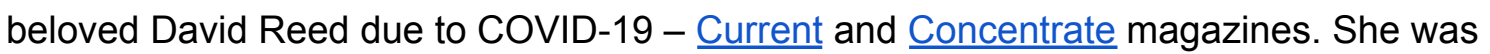
recently featured on a podcast in the Detroit Free Press, and will be appearing on another podcast in April 2021. Monica has appeared on Monica Morgan's radio show about Code Switching and Darwin Griffin television show both in February 2021.

Monica holds a Masters in Education from Central Michigan University. She prides herself on being a cool hip mom, cancer survivor, a divorce survivor, and a trusted advocate for those who need it. Monica's first book The COVID DIARIES hit Amazon February 2021.

Monica is passionate about voice over work and can be contacted through her website: www.monicahickson.com

\section{Favorites:}

Color: purple

Drink: chai tea

Love: family

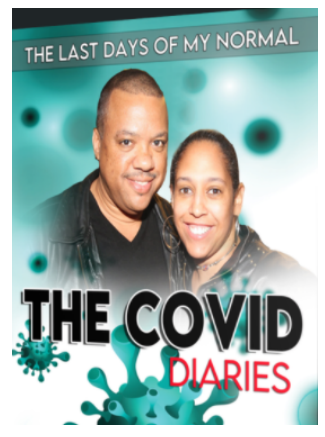

